\section{TRICUSPID VALVE} REPLACEMENT: POSTOPERATIVE AND LONG-TERM RESULTS
A series of 146 consecutive patients who underwent tricuspid valve replacement at the University Brugmann Hospital between 1967 and 1987 was reviewed. Mean age at operation was 51.4 years $( \pm 12.1$ years). Different types of prostheses were implanted including porcine and bovine pericardial bioprostheses and older and bileaflet mechanical valves. Most patients were severely disabled by their cardiac disease before operation, with $30.1 \%$ in New York Heart Association functional class III and 69.9\% in class IV. Operative mortality and hospital mortality rates (30 days) were high (16.4\%). Incremental risk factors for hospital death included icterus $(p<0.005)$, preoperative hepatomegaly ( $p=0.012$ ), and New York Heart Association functional class IV $(p=0.013)$. Multivariate analysis only selected preoperative icterus $(p<0.01)$ as being independently significantly related to hospital mortality. The hospital survivors were followed up for a median of 94 months. A complete follow-up was available for all patients except two for 30 months or more. At 30 months the only two significant parameters were the type of myocardial protection $(p=$ 0.024) and the year of operation (before 1977 or after [precardioplegia era or after], $p=0.011$ ). There were 70 late deaths during the entire follow-up period. The univariate (log-rank statistics) incremental risk factor for late death was the type of tricuspid prosthesis (Smeloff-Cutter and Kay-Shiley versus St. Jude Medical versus bioprosthesis) $(p=0.04)$. A trend was observed for the type of operative myocardial protection (normothermia and coronary perfusion) $(p=$ 0.06) and preoperative New York Heart Association functional class IV ( $p=$ 0.055). Actuarial survival was $74 \%$ at 60 months and $23.4 \%$ at 180 months. Cumulative follow-up added up to 1015 patient-years. In a more detailed analysis of the effect on survival of the type of tricuspid prosthesis, a significant difference was observed between the bioprostheses and some older mechanical prostheses (Smeloff-Cutter and Kay-Shiley) $(p=0.04)$ but not between the bioprostheses and the bileaflet valves $(p=0.15)$. When the follow-up period was stratified according to less than 7 years and more than 7 years of follow-up, no difference was observed for the first period, but for the late follow-up the new mechanical prostheses did better than the bioprostheses $(p=0.05)$, suggesting a degradation of the bioprostheses after 7 years and favoring mechanical prostheses for those patients with a good long-term prognosis. (J ThORAC CARDIOVASC SuRg 1995;110:672-9)

Guido J. Van Nooten, MD, ${ }^{a}$ Frank Caes, MD, ${ }^{a}$ Yves Taeymans, MD, ${ }^{\mathrm{b}}$

Yves Van Belleghem, MD, Katrien François, MD, ${ }^{a}$ Dirk De Bacquer, MSc, Frank E. Deuvaert, MD, ${ }^{c}$ Francis Wellens, MD, ${ }^{c}$ and Georges Primo, MD, ${ }^{c}$ Ghent and Brussels, Belgium
From the Departments of Surgery ${ }^{\mathrm{a}}$ and Cardiology, ${ }^{\mathrm{b}}$ University Hospital of Ghent, Ghent, Belgium, and the Department of Surgery, ${ }^{c}$ University Hospital Brugmann, Brussels, Belgium. Received for publication August 12, 1994.

Accepted for publication Dec. 29, 1994.

Address for reprints: Guido J. Van Nooten, MD, Cardiac Surgery Department, University Hospital Ghent, De Pintelaan 185, 9000 Ghent, Belgium.

Copyright (C) 1995 by Mosby-Year Book, Inc.

$0022-5223 / 95 \$ 5.00+0 \quad \mathbf{1 2 / 1 / 6 3 3 4 4}$
$\mathbf{Q}$ ince the start of tricuspid valve replacements in $\checkmark$ the early $1960 \mathrm{~s}$, nearly all types of prostheses have been used in the tricuspid position, with different results. In the absence of severe structural damage of the native valve, repair or annuloplasty should always be attempted. ${ }^{1}$ During the period of our study 173 tricuspid valve reconstructions were done at the same hospital. Nevertheless, nearly $45 \%$ of our patients with tricuspid valve disease required 
Table I. Clinical features of the 146 patients undergoing TVR

\begin{tabular}{lrr}
\hline \multicolumn{1}{c}{ Clinical feature } & $N$ & $\%$ \\
\hline NYHA class & & \\
III & 44 & 30.1 \\
IV & 102 & 69.9 \\
Rhythm & 122 & 83.5 \\
$\quad$ Atrial fibrillation & 22 & 15.1 \\
Sinus rhythm & 2 & 1.4 \\
$\quad$ Unknown & 80 & 54.8 \\
Hepatomegaly & 31 & 21.2 \\
Icterus & 66 & 45.2 \\
Peripheral edema & 21 & 14.4 \\
Ascites & 24 & 16.4 \\
Cyanosis & 143 & 97.9 \\
Cardiothoracic ratio $>0.5$ & & \\
\hline
\end{tabular}

valve replacement, more frequently in the early years. We reviewed and analyzed the results in our 146 patients with valve replacement to establish a strategy toward the optimal valve choice. As described by McGrath and colleagues, ${ }^{2}$ bioprostheses in the tricuspid position perform well up to 10 years after implantation, but can show some structural deterioration, and this finding was even more pronounced in younger patients in other series. ${ }^{3}$ Good long-term results with bileaflet mechanical valves could alter our policy of using preferentially a large bioprosthesis in the tricuspid position.

\section{Patients and methods}

All 146 patients who underwent tricuspid valve replacement (TVR) at the University Brugmann Hospital between 1967 and 1987 were included in the review. Our series included 32 male $(21.9 \%)$ and 114 female $(78.1 \%)$ patients with a mean age of 51.4 years (range 15 to 71 years, standard deviation 12.1). The clinical data of the patients in the TVR group are summarized in Table I. Rheumatic heart disease was the most frequent cause and was present in 102 patients (69.9\%). Ebstein's anomaly occurred in $4(2.7 \%)$, endocarditis in $3(2.1 \%)$, and in the remaining 37 patients $(25.3 \%)$ the disease process was considered to be functional. Eighty-eight $(60.3 \%)$ patients had tricuspid valve regurgitation only, 4 had pure stenosis $(2.7 \%)$, and $54(37.0 \%)$ had a combination of both, as assessed clinically, echocardiographically, hemodynamically, and perioperatively. Most of our patients had an advanced stage of heart valve disease, with 44 patients (30.1\%) in New York Heart Association (NYHA) functional class III and 102 patients $(69.9 \%$ ) in class IV or higher. Ascites was present in 21 patients (14.4\%), cyanosis in $24(16.4 \%)$, hepatomegaly in $80(54.8 \%)$, edema in $66(45.2 \%)$, and icterus in $31(21.2 \%)$. Concomitant cardiac procedures were necessary in 139 patients $(95.2 \%)$, as shown in Table II. Moreover, 59 patients
Table II. Associated cardiac procedures in 146 patients undergoing TVR

\begin{tabular}{lrr}
\hline \multicolumn{1}{c}{ Procedures done } & $N$ & $\%$ \\
\hline MVR & 93 & 63.6 \\
AVR, MVR & 26 & 17.8 \\
AVR & 2 & 1.3 \\
OMC & 2 & 1.3 \\
MVR, aortic valve repair & 1 & 0.7 \\
Thrombectomy left atrium & 5 & 3.4 \\
Thrombectomy right atrium & 1 & 0.7 \\
Mitral paravalvular leak closure & 2 & 1.3 \\
Aortic paravalvular leak closure & 1 & 0.7 \\
Atrial septum defect repair & 3 & 2.0 \\
Ventricular septum defect repair & 1 & 0.7 \\
Epicardial pacemaker & 2 & 1.4 \\
Total & 139 & 95.2 \\
\hline
\end{tabular}

$M V R$, Mitral valve replacement; $A V R$, aortic valve replacement; $O M C$, open mitral commissurotomy.

Table III. Previous cardiac operations in 146 patients undergoing TVR

\begin{tabular}{|c|c|c|c|}
\hline & & $N$ & $\%$ \\
\hline \multicolumn{4}{|l|}{ One procedure } \\
\hline \multicolumn{2}{|l|}{ MVR } & 13 & 8.9 \\
\hline \multicolumn{2}{|l|}{$\mathrm{CMC}$} & 16 & 10.9 \\
\hline \multicolumn{2}{|l|}{$\mathrm{OMC}$} & 12 & 8.2 \\
\hline \multicolumn{2}{|l|}{ AVR, MVR } & 5 & 3.4 \\
\hline \multicolumn{2}{|l|}{ AVR } & 2 & 1.4 \\
\hline \multicolumn{2}{|c|}{ OMC, tricuspid valve repair } & 3 & 2.0 \\
\hline \multicolumn{2}{|c|}{ MVR, tricuspid valve repair } & 2 & 1.4 \\
\hline \multicolumn{2}{|c|}{ AVR, MVR, tricuspid valve repair } & 1 & 0.7 \\
\hline \multicolumn{2}{|l|}{ AVR, MVR } & 1 & 0.7 \\
\hline \multicolumn{2}{|l|}{ OMC, OTC } & 1 & 0.7 \\
\hline \multicolumn{2}{|c|}{ Tricuspid valvectomy } & 1 & 0.7 \\
\hline \multicolumn{2}{|c|}{ Atrial septum defect repair } & 1 & 0.7 \\
\hline \multicolumn{2}{|l|}{ Pericardectomy } & 1 & 0.7 \\
\hline \multicolumn{2}{|l|}{ Total } & 59 & 40.4 \\
\hline \multicolumn{4}{|l|}{ Two procedures } \\
\hline First & Second & & \\
\hline $\mathrm{CMC}$ & $\mathrm{CMC}$ & 1 & 0.7 \\
\hline $\mathrm{CMC}$ & $\begin{array}{l}\text { AVR, MVR, tricuspid } \\
\text { valve repair }\end{array}$ & 1 & 0.7 \\
\hline AVR, MVR & AVR, MVR & 1 & 0.7 \\
\hline AVR, MVR & Paravalvular leak closure & 1 & 0.7 \\
\hline MVR & Paravalvular leak closure & 1 & 0.7 \\
\hline VSD repair & Residual VSD closure & 1 & 0.7 \\
\hline Total & & 6 & 4.1 \\
\hline
\end{tabular}

$M V R$, Mitral valve replacement; $C M C$, closed mitral commissurotomy; $O M C$, open mitral commissurotomy; $A V R$, atrial valve replacement; $O T C$, open tricuspid commissurotomy; VSD, ventricular septal defect.

(40.4\%) had undergone one previous cardiac operation and 6 had undergone two (4.1\%), as shown in Table III.

We used different types of prostheses in the tricuspid position: 69 bioprostheses (47.3\%) and 77 mechanical valves $(52.7 \%)$. During the 1960 s and early 1970 s, only 
Table IV. Univariate analysis of clinical variables related to hospital mortality

\begin{tabular}{|c|c|c|c|}
\hline & Alive & Dead & $\begin{array}{c}p \\
\text { Value } \\
\end{array}$ \\
\hline Age $(\mathrm{yr}$, mean $\pm \mathrm{SD})$ & $51.5 \pm 12.6$ & $52.7 \pm 9.6$ & NS \\
\hline \multicolumn{4}{|l|}{ Sex } \\
\hline Female & 99 & 15 & \\
\hline Male & 23 & 9 & 0.04 \\
\hline \multicolumn{4}{|l|}{ Previous operation } \\
\hline Absent & 69 & 13 & \\
\hline Present & 53 & 11 & NS \\
\hline \multicolumn{4}{|l|}{ Rheumatic disease } \\
\hline Absent & 32 & 12 & \\
\hline Present & 88 & 14 & NS \\
\hline \multicolumn{4}{|l|}{ Tricuspid disease } \\
\hline Regurgitation & 71 & 17 & \\
\hline Stenosis & 51 & 7 & NS \\
\hline \multicolumn{4}{|l|}{ NYHA class } \\
\hline III & 42 & 2 & \\
\hline IV & 80 & 22 & 0.013 \\
\hline \multicolumn{4}{|l|}{ Ascites } \\
\hline Absent & 107 & 18 & \\
\hline Present & 15 & 6 & NS \\
\hline \multicolumn{4}{|l|}{ Cyanosis } \\
\hline Absent & 105 & 17 & \\
\hline Present & 17 & 7 & NS \\
\hline \multicolumn{4}{|l|}{ Icterus } \\
\hline Absent & 102 & 13 & \\
\hline Present & 20 & 11 & 0.005 \\
\hline \multicolumn{4}{|l|}{ Hepatomegaly } \\
\hline Absent & 61 & 5 & \\
\hline Present & 61 & 19 & 0.012 \\
\hline \multicolumn{4}{|l|}{ Edema } \\
\hline Absent & 65 & 15 & \\
\hline Present & 57 & 9 & NS \\
\hline
\end{tabular}

$S D$, Standard deviation; NS, not significant.

old-style mechanical valves (27 Smeloff-Cutter, ${ }^{*} 14$ KayShiley, $\dagger$ and 1 DeBakey + ) were available. Before 1977, 23 Björk-Shileyt tilting-disc valves were implanted in the tricuspid position. Since 1975 , porcine xenografts (31 Carpentier-Edwards $\S$ and 25 Hancock $\|$ ) have been currently used. Between 1979 and 1981, 12 St. Jude MedicalT mechanical valves were inserted in the tricuspid position. Finally, some bovine pericardial bioprostheses (9 Carpentier-Edwards and 4 Mitroflow) were implanted between 1978 and 1983.

All operations were done through median sternotomy with the use of standard cardiopulmonary bypass (CPB). Before 1977, normothermic CPB with coronary perfusion and mild systemic hypothermia was used, whereas more

\footnotetext{
* Cutter Biological, Berkeley, Calif.

$\uparrow$ Shiley, Inc., Irvine, Calif.

$\ddagger$ Surgitool, Inc, Pittsburgh, Pa.

§ Baxter Healthcare Corp., Edwards Division, Santa Ana, Calif.

|| Johnson \& Johnson Cardiovascular, King of Prussia, Pa.

II St. Jude Medical, Inc., St. Paul, Minn.
}

recently moderate hypothermia and cold antegrade St. Thomas' Hospital cardioplegic solution has been used. Anticoagulation therapy with warfarin (Coumadin) was started on the first postoperative day and continued life-long in patients with mechanical valves or chronic atrial fibrillation; otherwise it was stopped after 3 months. Several clinical parameters and surgical parameters were recorded retrospectively.

Statistical analysis. Continuous variables are expressed as mean and standard deviations. Variables entered into risk-factor analysis included age, gender, previous operation, rheumatic disease, tricuspid disease, NYHA functional class, ascites, cyanosis, icterus, hepatomegaly, edema, duration of aortic clamping, duration of $\mathrm{CPBs}$, myocardial protection, year of operation, and type of prosthesis. For statistical power considerations the types of tricuspid prostheses were grouped into three categories: bioprostheses, old mechanical prostheses, and new mechanical prostheses. Univariate comparisons between the groups of survivors and nonsurvivors at 30 days and 30 months after operation were done by Fisher's exact test and Student's $t$ test. A stepwise multivariate logistic regression was used to identify a subset of independent variables predictive of hospital and 30-month mortality (Systat 5.2 statistical program, Systat, Inc., Evanston, Ill.). The level for entrance to or removal from the model was set at 0.05 . Univariate analysis of survival curves was done by the log-rank test. ${ }^{4}$

\section{Results}

Hospital mortality. Twenty-four patients died during hospitalization, yielding a hospital mortality rate of $16.4 \%$. Cardiac failure was responsible in 11 patients (45.8\%), bleeding in $3(12.5 \%)$, arrhythmias in $3(12.5 \%)$, multiple organ failure in $2(8.3 \%)$, respiratory insufficiency in $1(4.2 \%)$, sepsis in 1 (4.2\%), and valvular thrombosis in $1(4.2 \%)$; sudden death of unknown origin occurred in 2 patients $(8.4 \%)$. Univariate analysis (Table IV) showed presence of icterus ( $p=0.005)$, presence of hepatomegaly $(p=0.012)$, NYHA class IV $(p=0.013)$, and male gender $(p=0.04)$ to be associated with hospital mortality. The cause (rheumatic or not) of the tricuspid valve disease and the pathologic condition of the tricuspid valve (regurgitant or not) showed no relation with the in-hospital outcome. Among the perioperative parameters no relation was found at all with early survival (Table V).

Valve-related complications. Paravalvular leakage developed in 4 patients $(3.3 \%)$. Twice the tricuspid prosthesis was concerned: once in a Smeloff-Cutter and once in a Björk-Shiley valve. The first patient died without surgical intervention and the latter underwent successful replacement of the affected prosthesis. Late endocarditis occurred in 3 patients $(2.5 \%) 36,54$, and 96 months, respec- 
tively, after operation. This involved 1 CarpentierEdwards mitral prosthesis, 1 Kay-Shiley tricuspid prosthesis, and both mitral and tricuspid St. Jude Medical prostheses in the last patient. All patients were treated medically. The first 2 patients recovered and the latter died of a cerebrovascular accident. Major anticoagulant-related hemorrhage (necessitating hospitalization and transfusion) occurred in 13 patients $(10.7 \%)$. Four cases were fatal: 2 digestive, 1 cerebral, and 1 posttraumatic.

Reoperation and valve trombosis. Late tricuspid valve reoperation was required in 11 of the hospital survivors (9\%) (Table VI). The mean interval to reoperation was 83.8 months (range 0.27 to 161 months). Three patients did not survive reoperation (27.3\%); one died of cardiac failure, another of respiratory failure, and in the third patient the cause remains unknown. Prosthetic valve thrombosis occurred in 11 patients. Two cases of valve thrombosis on postoperative days 6 and 8 were fatal. Nine patients had late thrombosis from 5 to 132 months after primary TVR. The types of prosthesis involved included 4 Smeloff-Cutter valves ( 3 in the tricuspid and 1 in the mitral position), 3 Björk-Shiley valves (2 in the tricuspid and 1 in the mitral and tricuspid positions), and 1 St. Jude Medical valve and 1 Carpentier-Edwards valve in the tricuspid position. Of these 9 patients, 6 died before surgical intervention and the other 3 underwent successful replacement of the thrombosed prosthesis. Actuarial freedom from death and reoperation with a tricuspid valve prosthesis is shown in Fig. 1 for the different valve types.

Thirty-month mortality. A total of 120 hospital survivors were followed up for at least 30 months (this includes all patients except two, who were followed up for 27 and 29 months, respectively). An interim analysis at 30 months showed only a significant different survival for the type of myocardial protection (hypothermia, 8 of 68 versus normothermia, 13 of $43 ; p=0.024$ ) and the use of cardioplegia (before 1977, 18 of 65 versus after 1977, 5 of $55 ; p=$ 0.011). A trend was also shown for NYHA functional class before operation (class III, 4 of 41 versus class IV, 19 of $79 ; p=005$ ) (Table VII). A multivariate logistic regression at 30 months selected the absence of myocardial protection and the presence of tricuspid valve stenosis as the two factors positively and independently related to mortality $(p=$ 0.015 and $p=0.048$, respectively).

Late survival. Late death occurred in 70 of the 122 hospital survivors of the original TVR (57.4\%).
Table V. Univariate analysis of perioperative variables related to hospital mortality

\begin{tabular}{lccc}
\hline & Alive & Dead & $\begin{array}{c}p \\
\text { Value }\end{array}$ \\
\hline $\begin{array}{l}\text { Aortic clamp time } \\
\text { (min) }\end{array}$ & $66.2 \pm 32.5$ & $68.2 \pm 36.1$ & NS \\
$\begin{array}{l}\text { Duration of CPB } \\
\text { (min) }\end{array}$ & $113 \pm 31.1$ & $141.3 \pm 58.5$ & NS \\
Myocardial protection & & & \\
$\quad$ Normothermia & 43 & 11 & 0.99 \\
$\quad$ Hypothermia & 70 & 13 & \\
Tricuspid prosthesis & & & \\
$\quad$ Old mechanical & 33 & 9 & 0.49 \\
$\quad$ New mechanical & 29 & 6 & \\
Bioprosthesis & 60 & 9 & \\
\hline
\end{tabular}

NS, Not significant.

Modes included cardiac failure in 25 patients (35.7\%), sudden death in $10(14.3 \%)$, neurologic events in $5(7.1 \%)$, valvular thrombosis in $5(7.1 \%)$, anticoagulant-related bleeding in $4(5.7 \%)$, valvular prosthesis dysfunction in $3(4.3 \%)$, infective endocarditis in $2(2.8 \%)$, arrhythmia in $1(1.4 \%)$, noncardiac causes in $8(11.4 \%)$, and unknown causes in 7 $(10.0 \%)$. Cumulative follow-up added up to 1015 patient/years and the median survival time for hospital survivors was 116 months. Two patients were lost to follow-up ( $98.4 \%$ complete). The actuarial survival at 60 months remained $74.0 \%$ and decreased at 180 months to $23.4 \%$ (Fig. 2). Of the 52 long-term survivors, $11(21.2 \%)$ are in NYHA functional class I, $32(61.5 \%)$ in class II, $6(11.5 \%)$ in class III, and the remaining $3(5.8 \%)$ in class IV. Thirty-nine patients $(75 \%)$ have atrial fibrillation, 7 have regular sinus rhythm (13.5\%), 5 had a pacemaker implanted $(9.6 \%)$, and in 1 patient the rhythm remains uncertain (1.9\%). Univariate analysis (log-rank statistics) revealed the type of tricuspid prosthesis (Smeloff-Cutter and Kay-Shiley versus St. Jude Medical and bioprosthesis) $(p=0.04)$ as an incremental risk factor for late death. A trend was observed for the type of operative myocardial protection (normothermia and coronary perfusion) $(p=0.06)$ and preoperative NYHA functional class IV $(p<0.06)$. A more detailed analysis of the effect on survival of the type of tricuspid prosthesis showed a significant difference between the bioprosthesis and the older mechanical prostheses (Smeloff-Cutter and Kay-Shiley) ( $p=0.04$ ) but not between the bioprosthesis and the new prosthesis $(p=0.15)$ (Fig. 1). When the follow-up period was stratified according to less than 7 years and 7 or more years of follow-up, no significant difference 


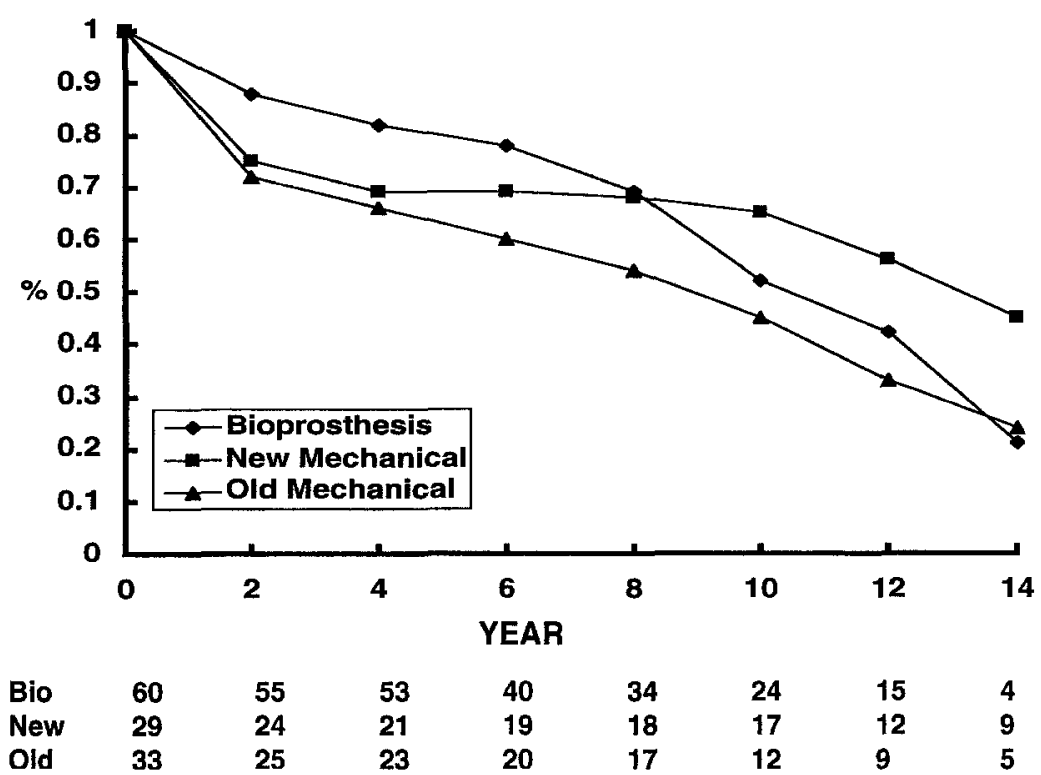

Fig. 1. Actuarial freedom from death and reoperation with tricuspid prosthesis for different valve types. Bio, Bioprosthesis.

Table VI. Reoperations

\begin{tabular}{|c|c|c|c|c|c|}
\hline Original valve & $\begin{array}{l}\text { Reason for } \\
\text { malfunction }\end{array}$ & $\begin{array}{l}\text { Interval to } \\
\text { reoperation }\end{array}$ & $\begin{array}{l}\text { Reoperation } \\
\text { procedure }\end{array}$ & $\begin{array}{l}\text { New tricuspid } \\
\text { prosthesis }\end{array}$ & Status \\
\hline \multirow[t]{3}{*}{ Smeloff-Cutter } & Pannus & $83 \mathrm{mo}$ & TVR & St. Jude Medical & Alive \\
\hline & Pannus & $89 \mathrm{mo}$ & TVR & St. Jude Medical & Alive \\
\hline & Thrombus & 96 mo & TVR & Carpentier-Edwards & Died \\
\hline \multirow[t]{4}{*}{ Björk-Shiley } & Thrombus & $16 \mathrm{mo}$ & TVR & Smeloff-Cutter & Alive \\
\hline & Pannus & $161 \mathrm{mo}$ & TVR & Carpentier-Edwards & Alive \\
\hline & Thrombus & $25 \mathrm{mo}$ & TVR, MVR & Smeloff-Cutter & Alive \\
\hline & Thrombus & 8 days & TVR & Smeloff-Cutter & Died \\
\hline Kay-Shiley & Pannus & $45 \mathrm{mo}$ & TVR & Smeloff-Cutter & Alive \\
\hline \multirow[t]{3}{*}{ Carpentier-Edwards } & PVF & $133 \mathrm{mo}$ & TVR & Carpentier-Edwards & Alive \\
\hline & PVF & $142 \mathrm{mo}$ & TVR & None & Died \\
\hline & Thrombus & $132 \mathrm{mo}$ & TVR, MVR, AVR & Carpentier-Edwards & Alive \\
\hline
\end{tabular}

$\overline{M V R}$, Mitral valve replacement; $P V F$, primary valve failure; $A V R$, aortic valve replacement.

was observed for the first period but for the late follow-up the new mechanical prosthesis did better than the bioprosthesis $(p=0.05)$. A stepwise multiple logistic regression test selected the presence of icterus as the sole independent predictor of late death $(p<0.01)$.

\section{Discussion}

The operative mortality rate of $16.4 \%$ in our series is comparable with those in literature reports, which range from less than $10 \%$ to more than $50 \%$ for both isolated and combined TVR. ${ }^{5-19}$ A reduction in mortality rate in the more recent era was also observed by Livi and colleagues ${ }^{20}$ and related to improvement of perioperative myocardial protec- tion and postoperative management. Almost half of our early deaths were caused by cardiac failure related to severe depression of myocardial function, which was especially noticed in the precardioplegia group as reported in most series. ${ }^{6-8,11,14,16,18-21}$ This was also confirmed indirectly in our series by the significant relation between the year of intervention and the survival (before 1977 versus after 1977). A number of preoperative variables were identified as univariate predictors of high risk for hospital death after TVR: male gender, NYHA functional class IV, hepatomegaly, and icterus. Poor survival in men, also detected by other authors, remains unexplained. ${ }^{19,22}$ The increased early risk for TVR in patients with advanced functional disability has been 


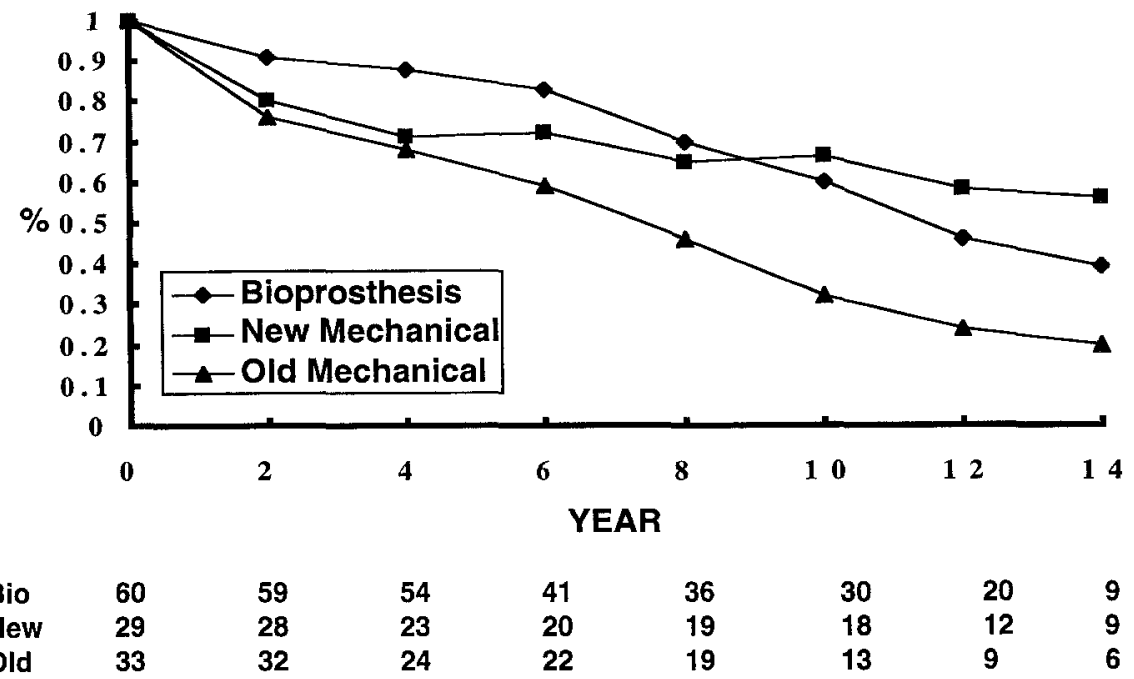

Fig. 2. Actuarial survival curves according to type of prosthesis. Bio, Bioprosthesis.

documented in some reports. ${ }^{9,18-20,22}$ Preoperative hepatomegaly and icterus likely represent hepatic congestion resulting from severe failure of the right side of the heart and have been associated with high early mortality rates. ${ }^{19,22}$

Late death occurred in $57 \%$ of the hospital survivors of the original TVR. More than one third of these patients died of cardiac failure, which suggests progression of cardiomyopathy despite successful surgical valve replacement. ${ }^{9,17,18}$ Significant univariate risk factors for late death were the use of a Smeloff-Cutter or Kay-Shiley tricuspid prosthesis, myocardial protection by normothermia and coronary perfusion, and preoperative NYHA functional class IV. Intraoperative myocardial protection has been reported to influence operative mortality, but not late death. ${ }^{21}$ Advanced functional disability seems to have an ominous influence not only on early but also on long-term results of TVR., ${ }^{9,19,21}$ The higher prevalence of tricuspid valve thrombosis in older mechanical valves has been confirmed by several authors. ${ }^{6,9,16,21,23}$ Likewise, a low prevalence of valve-related thromboembolism with the St. Jude Medical valve in patients with correctly regulated anticoagulation therapy has been reported. ${ }^{24-26}$ The long-term results, 14 years after implantation of the bileaflet valve, equal at approximately 8 years the good score of the bioprosthesis, to improve the late results, but this requires further follow-up. On the other hand, degeneration of the bioprosthesis in the tricuspid position is exceptional during the first 10 years and becomes more pro-
Table VII. Univariate analysis of variables related to 30-month mortality

\begin{tabular}{|c|c|c|c|}
\hline & Alive & Dead & $\begin{array}{c}p \\
\text { Value }\end{array}$ \\
\hline Age $(y r$, mean $\pm S D)$ & $50.8 \pm 11.9$ & $52.2 \pm 15.0$ & NS \\
\hline \multicolumn{4}{|l|}{ Sex } \\
\hline Female & 79 & 18 & \\
\hline Male & 18 & 5 & NS \\
\hline \multicolumn{4}{|l|}{ Rheumatic disease } \\
\hline Absent & 16 & 3 & \\
\hline Present & 80 & 19 & NS \\
\hline \multicolumn{4}{|l|}{ NYHA } \\
\hline III & 37 & 4 & \\
\hline IV & 60 & 19 & 0.05 \\
\hline \multicolumn{4}{|l|}{ Ascites } \\
\hline Absent & 85 & 21 & \\
\hline Present & 12 & 2 & NS \\
\hline \multicolumn{4}{|l|}{ Cyanosis } \\
\hline Absent & 84 & 20 & \\
\hline Present & 13 & 3 & NS \\
\hline \multicolumn{4}{|l|}{ Icterus } \\
\hline Absent & 83 & 18 & \\
\hline Present & 14 & 5 & NS \\
\hline \multicolumn{4}{|l|}{ Hepatomegaly } \\
\hline Absent & 48 & 12 & \\
\hline Present & 49 & 11 & NS \\
\hline \multicolumn{4}{|l|}{ Year of operation } \\
\hline Before 1977 & 47 & 18 & \\
\hline After 1977 & 51 & 5 & 0.01 \\
\hline \multicolumn{4}{|l|}{ Myocardial protection } \\
\hline Normothermia & 60 & 13 & \\
\hline Hypothermia & 30 & 8 & 0.02 \\
\hline \multicolumn{4}{|l|}{ Tricuspid prosthesis } \\
\hline Old mechanical & 24 & 9 & \\
\hline New mechanical & 22 & 7 & NS \\
\hline Bioprosthesis & 51 & 7 & \\
\hline
\end{tabular}

$\widehat{S D}$, Standard deviation; $N S$, not significant. 
nounced more than 10 years after initial implantation, especially in children. ${ }^{2,3,27,28}$ In our series, two cases of primary valve failure necessitated replacement, both more than 10 years after initial implantation. Other valve-related complications such as endocarditis and paravalvular leakage were rare, regardless of the type of tricuspid prosthesis.

In conclusion, TVR carries a high operative risk and low likelihood of long-term survival, both influenced by preoperative and perioperative variables. Mechanical disc or ball valves in the tricuspid position are prone to dysfunction by pannus formation or thrombosis. ${ }^{22,29,30}$ Moreover, Smeloff-Cutter and Kay-Shiley prostheses are incremental risk factors for late death. Because bioprostheses in the tricuspid position have a low risk of valve-related events, we preferred a large-sized bioprosthesis when TVR was mandatory, although the confirmation of better long-term results (14 years) of the St. Jude Medical valves altered our valve choice in some particular young patients with a good longterm prognosis.

\section{REFERENCES}

1. Carpentier A, Deloche A, Hanania G, et al. Surgical management of acquired tricuspid valve disease. $\mathbf{J}$ Thorac Cardiovasc Surg 1974;67:53-65.

2. McGrath LB, Chen C, Bailey BM, Fernandez J, Laub GW, Adkins MS. Early and late phase events follow in bioprosthetic tricuspid valve replacement. J Card Surg 1992;7:245-9.

3. Kawachi Y, Tominaga R, Hisahara M, Nakashima A, Yasui $\mathrm{H}$, Tokunaga $\mathrm{K}$. Excellent durability of the Hancock porcine bioprosthesis in the tricuspid position: a sixteen-year follow-up study. J THORAC CARDIOVASC SURG 1992;104:1561-6.

4. Cox DR. Regression models and life-tables. J R Stat Soc 1972;34:187-220.

5. McIntosh CL, Michaelis LL, Morrow AG, Itscoitz SB, Redwood DR, Epstein SE. Atrioventricular valve replacement with the Hancock porcine xenograft: a five year clinical experience. Surgery 1975;78:768-75.

6. Sanfelippo PM, Giuliani ER, Danielson GK, Wallace RB, Pluth JR, McGoon DC. Tricuspid valve prosthetic replacement: early and late results with the Starr-Edwards prosthesis. J Thorac CardiovasC SURG 1976;71:441-5.

7. Kouchoukos NT, Stephenson LW. Indications for and results of tricuspid valve replacement. Adv Cardiol 1976:17:199-206.

8. Breyer RH, McClenathan JH, Michaelis LL, McIntosh $\mathrm{CL}$, Morrow AG. Tricuspid regurgitation: a comparison of nonoperative management, tricuspid annuloplasty and tricuspid valve replacement. J THORaC Cardiovasc Surg 1976;72:867-74.

9. Jugdutt BI, Fraser RS, Lee SJ, Rossall RE, Callaghan JC. Long-term survival after tricuspid valve replacement: results with seven different prostheses. J THORaC Cardiovasc Surg 1977;74:20-7.

10. Peterffy A, Henze A, Jonasson R, Björk VO. Clinical evaluation of the Björk-Shiley tilting disk valve in tricuspid position. Scand J Thorac Cardiovasc Surg 1978;12:179-87.

11. Egloff L, Brugger JJ, Rothlin M, Turnia M, Senning A. Bioprosthetic replacement of the tricuspid valve. Thorac Cardiovasc Surg 1982;30:281-3.

12. Khonsari S, Starr A. Acquired disease of the tricuspid valve. In: Sabiston DC, Spencer FC, eds. Gibbon's surgery of the chest. 4th ed. Philadelphia: WB Saunders, 1983:1211-24.

13. Björk VO, Henze A, Peterffy A. Can a mechanical heart valve be used in the tricuspid position: experience with the Björk-Shiley tilting disc valve in 70 patients. Eur Heart J 1980;1:55-61.

14. Kratz JM, Crawford FA Jr, Stroud MR, Appleby DC $\mathrm{Jr}$, Hanger KH. Trends and results in tricuspid valve surgery. Chest 1985;88:837-40.

15. Kirklin JW, Barratt-Boyes BG. Tricuspid valve disease. In: Cardiac surgery. 1st ed. New York: Churchill Livingstone, 1986:447-59.

16. Wellens F, Goldstein J. Tricuspid valve replacement. Cardiovasc Clin 1987;17:111-5.

17. Michel PL, Houdart E, Ghanem G, Badaoui G, Hage A, Acar J. Combined aortic, mitral and tricuspid surgery: results in 78 patients. Eur Heart J 1987;8:45763.

18. Barratt-Boyes BG, Rutherford JD, Whitlock RML, Pemberton JR. A review of the surgery for the acquired tricuspid valve disease, including an assessment of the stented semilunar homograft valve, and the results of the operation for multivalvular disease. Aust N Z J Surg 1988;58:23-34.

19. Baughman KL, Kallman CH, Yurchak PM, Daggett WM, Buckley MJ. Predictors of the survival after tricuspid valve surgery. Am J Cardiol 1984;54:13741.

20. Livi U, Bortolotti U, Rizzoli G, Valfré C, Mazzucco A, Gallucci V. Surgical treatment of patients with triple heart valve disease: results and analysis of the factors affecting the surgical outcome. Thorac Cardiovasc Surg 1982;30:288-91.

21. Thorburn CW, Morgan JJ, Shanahan MX, Chang VP. Long-term results of tricuspid valve replacement and the problem of prosthetic valve thrombosis. Am J Cardiol 1983;51:1128-32.

22. McGrath LB, Gonzalez-Lavin L, Bailey BM, Grunkemeier GL, Fernandez J, Laub GW. Tricuspid valve operations in 530 patients: twenty-five-year assess- 
ment of early and late phase events. J THORAC CARDIOVASC SURG 1990;99:124-33.

23. Van der Veer JB, Rhyneer GS, Hodam RP, Kloster FE. Obstruction of tricuspid ball-prosthesis. Circulation 1971;44(Suppl):I62-7.

24. Hunt D, Sloman G, Sutton L. The St. Jude Medical valve: the Australian experience. Med J Aust 1981;19: 276-8.

25. Nicoloff DM, Emery RW, Arom KV, et al. Clinical and hemodynamic results with the St. Jude Medical cardiac valve prosthesis: a three-year experience. J Thorac Cardiovasc Surg 1981;82:674-83.

26. Singh AK, Christian FD, Williams DO, et al. Follow-up assessment of the St. Jude Medical prosthetic valve in the tricuspid position: clinical and hemodynamic results. Ann Thorac Surg 1984;37:324-7.

27. Dunn JM. Porcine valve durability in children. Ann Thorac Surg 1981;32:357-68.

28. Pasque M, Williams WG, Coles JG, et al. Tricuspid valve replacement in children. Ann Thorac Surg 1987; 44:164-8.

29. Boskovic D, Elezovic I, Boskovic D, Simin N, Rolovic Z, Josipovic V. Late thrombosis of the Björk-Shiley tilting disc valve in the tricuspid position: thrombolytic treatment with streptokinase. J THORAC CARDIOvasC SURG 1986;91:1-8.

30. Schoevaerdts JC, Jaumin P, Piret L, et al. Tricuspid valve surgery. J Cardiovasc Surg 1977;18:397-9.

\section{1-800-55-MOSBY}

This number links you to the full text of articles published in over 25,000 journals, including all Mosby journals. MOSBY Document Express $^{\text {Ge }}$, a rapid response information retrieval service, provides quick turnaround, 24-hour availability, and speedy delivery methods. For inquiries and pricing information, call our toll-free, 24-hour order line: 1-800-55-MOSBY; outside the United States: 415-259-5046; fax: 415-259-5019; E-mail: mosbyexp@class.org. 